\title{
The Role of Endothelin Converting Enzyme Inhibition during Group B Streptococcus-Induced Pulmonary Hypertension in Newborn Piglets
}

\author{
CRISTINA T. NAVARRETE, CARLOS DEVIA, ANDREA C. LESSA, DOROTHY HEHRE, \\ KAREN YOUNG, OCTAVIO MARTINEZ, EDUARDO BANCALARI, AND CLEIDE SUGUIHARA \\ Department of Pediatrics, Division of Neonatology [C.T.N., C.D., A.C.L., D.H., K.Y., E.B., C.S.], Division of \\ Orthopedics and Rehabilitation [O.M.], University of Miami School of Medicine, Miami, Florida 33101, U.S.A.
}

\begin{abstract}
An endothelin-converting enzyme mediates the conversion from low-potency pro-endothelin to potent endothelin-1 (ET-1). Increased ET-1 levels have been observed in pulmonary hypertension of various etiologies in infants. We hypothesized that increased ET-1 levels induce pulmonary hypertension during group B Streptococcus (GBS) infusion, and this can be attenuated by the administration of an endothelin-converting enzyme inhibitor (ECEI). Twenty-two unanesthetized, chronically instrumented newborn piglets received a continuous infusion of GBS $\left(3.5 \times 10^{8}\right.$ colony-forming units $\left./ \mathrm{kg} / \mathrm{min}\right)$ while exposed to $100 \%$ $\mathrm{O}_{2}$. They were randomly assigned to receive a placebo (PL) or an ECEI (phosphoramidon, $30 \mathrm{mg} / \mathrm{kg}$ i.v.) $15 \mathrm{~min}$ after sustained pulmonary hypertension. Comparison of hemodynamic measurements and arterial blood gases at baseline and over the first 210 min from the onset of pulmonary hypertension was performed between groups. GBS infusion caused significant increases in mean pulmonary artery pressure, pulmonary vascular resistance (PVR), systemic vascular resistance (SVR), and PVR/SVR, and significant decreases in cardiac output, $\mathrm{pH}$, and base excess. After the administration of ECEI, a significant reduction in pulmonary artery pressure $(p<0.0001)$, PVR $(p<0.001)$, and PVR/SVR $(p<0.01)$ and an improvement in cardiac output $(p$ $<0.01)$ were observed during GBS infusion. The decrease in $\mathrm{pH}$ $(p<0.001)$ and base excess $(p<0.001)$ during GBS infusion was less marked after the administration of ECEI compared with
\end{abstract}

\section{ABSTRACT}

the PL. Plasma ET-1 levels were obtained in 20 additional piglets; levels were significantly lower in the ECEI compared with PL after $3 \mathrm{~h}$ of GBS infusion $(p<0.02)$. All animals in the ECEI group survived the study period as opposed to $25 \%$ survival in the PL group $(p<0.001)$. These data suggest that the increased circulating ET-1 levels mediate, in part, the GBSinduced pulmonary hypertension. (Pediatr Res 54: 387-392, 2003)

Abbreviations
BE, base excess
ECE, endothelin-converting enzyme
ECEI, endothelin-converting enzyme inhibitor
ET-1, endothelin-1
GBS, group B Streptococcus
PL, placebo
Ppa, pulmonary artery pressure
Psa, systemic pressure
Pra, right atrial pressure
Pwp, pulmonary wedge pressure
CO, cardiac output
PVR, pulmonary vascular resistance
SVR, systemic vascular resistance
ABG, arterial blood gas
CPB, cardiopulmonary bypass

ratory distress syndrome, and lung hypoplasia (1). Although striking differences exist among these conditions, they can share common pathophysiologic features, including high pulmonary vascular resistance leading to extrapulmonary right-toleft shunting of blood across the ductus arteriosus or foramen ovale and hypoxemia (2). The incidence is 1.9 in every 1,000 live births $(1,2)$ and it causes significant morbidity and mortality.

The mechanisms that cause severe pulmonary hypertension after birth are characterized by active vasoconstriction, vascular smooth muscle hypertrophy, decreased vascular development, or combinations of the above (2). The endothelium has
Correspondence: Cleide Suguihara, M.D., University of Miami School of Medicine, Department of Pediatrics (R-131), PO Box 016960, Miami, FL 33101, U.S.A.; e-mail: csuguihara@miami.edu

Supported by the University of Miami, "Project: New Born," and an Advancing Newborn Medicine Fellows Research Grant from Forest Pharmaceuticals, Inc.

Presented, in part, at the Society for Pediatric Research, May 2001, Baltimore Maryland, U.S.A.

DOI: 10.1203/01.PDR.0000078272.77816.1E 
been established as a central player by releasing opposing mediators of vascular tone. In pathologic states, the predominant release of vasoconstrictors (thromboxanes, leukotrienes, and endothelin) over vasodilators (nitric oxide and prostacyclin) promotes increased vascular tone and subsequent hypertension. Among the known vasoconstrictors, ET-1 is the most potent $(1,3$, 4). In infants with persistent pulmonary hypertension of varied etiologies, elevated ET-1 levels were demonstrated, and it had a positive correlation with disease severity (4). ET-1 acts through two membrane receptor proteins, $\mathrm{ET}_{\mathrm{A}}$ and $\mathrm{ET}_{\mathrm{B}}$. $\mathrm{ET}_{\mathrm{A}}$ mediates vasoconstriction. There are two $\mathrm{ET}_{\mathrm{B}}$ receptor subtypes: $\mathrm{ET}_{\mathrm{B} 1}$, which is located on endothelial cells, mediates vasodilatation through the nitric oxide and prostacyclin pathways, and $\mathrm{ET}_{\mathrm{B} 2}$, which is located on vascular smooth muscle cells, mediates vasoconstriction (5). Various studies in different animal models of pulmonary hypertension have demonstrated that nonselective and selective ET receptor blockade results in attenuation of pulmonary hypertension. However, this amelioration in the pulmonary hypertension was accompanied by a significant decrease in systemic arterial pressure $(3,6,7)$.

Because ET-1 is produced from a two-step cleavage process and ECE is known to catalyze the cleavage of less potent big ET to potent ET-1, ECE inhibition is a plausible treatment alternative. A study using phosphoramidon, an ECE inhibitor, in a CPB pig model, showed attenuation of pulmonary hypertension without affecting the systemic arterial blood pressure (8).

Elevated ET-1 levels were reported in various studies in adult and neonatal animal models of Gram-negative and -positive sepsis (9-11). In the neonatal period, however, the most significant pathogen that causes early-onset fulminant sepsis and pulmonary hypertension is the Gram-positive cocci GBS (12). GBS produces significant sustained elevation of pulmonary artery pressure and marked decrease in cardiac output and partial pressure of arterial oxygen $\left(\mathrm{PaO}_{2}\right)$, followed by metabolic acidosis in newborn piglets (13). We, therefore, hypothesized that increased ET-1 levels induce the pulmonary hypertension observed during GBS infusion in newborn piglets and this can be attenuated by the administration of an ECEI. Our objective was to determine the role of ET-1 on GBS-induced pulmonary hypertension by blocking the production of ET-1 with the ECEI phosphoramidon.

\section{MATERIALS AND METHODS}

Animals. Twenty-two newborn Yorkshire piglets were obtained from a local farmer. They were randomly assigned to the PL or to the ECEI group. The procedures used in their care and handling were in accordance with the guidelines of the National Institutes of Health and the study protocol was reviewed and approved by the Animal Care and Use Committee of the University of Miami.

Animal instrumentation and hemodynamic and blood gas measurements. Anesthesia induction and maintenance was obtained using isoflurane at $1-2 \%$ in $\mathrm{O}_{2}$ at $2-3 \mathrm{~L} / \mathrm{min}$ via a mask and then a $3.5 \mathrm{~F}$ endotracheal tube (Mallinckrodt, St. Louis, MO, U.S.A.) for the duration of the surgery. The femoral artery was cannulated with a $5 \mathrm{~F}$ double-lumen catheter (Umbili-cath, UT Medical Products, West Midvale, UT,
U.S.A.) and used for Psa monitoring, bacterial infusion, and blood sampling. The femoral vein was cannulated with a $5 \mathrm{~F}$ Swan-Ganz thermodilution catheter (Edwards Life Science, Irvine, CA, U.S.A.) advanced to a pulmonary artery branch under fluoroscopic guidance and used for Ppa and Pwp, right Pra, and CO measurements. The catheters were tunneled to the piglet's dorsum, secured in a s.c. pocket, and flushed daily with heparinized saline.

Ppa, Psa, Pra, and Pwp were measured with the use of pressure transducers (Model P23, Gould, Cleveland, OH, U.S.A.) and recorded on a multichannel recorder (Model 2800, Gould). $\mathrm{CO}$ was measured by thermodilution technique using a cardiac output computer (Model 9510-A, Edwards Laboratories, Santa Ana, CA, U.S.A.). ABG were determined by using a blood gas analyzer (Model 238, Ciba-Corning, Essex, England) and corrected for core temperature. PVR was calculated as $(\mathrm{Ppa}-\mathrm{Pwp}) /(\mathrm{CO} / \mathrm{kg})$ and systemic vascular resistance as (Psa - Pra $) /(\mathrm{CO} / \mathrm{kg})$.

Bacterial preparation. Group B $\beta$-hemolytic streptococci type $\mathrm{I} a / \mathrm{c}$ isolated from an infected neonate were cultured in Todd-Hewitt broth for $18 \mathrm{~h}$ at $37^{\circ} \mathrm{C}$. The organisms were collected by centrifugation, washed, and resuspended in sterile Ringer's lactate solution with 5\% dextrose at a concentration determined by OD measurements to be equivalent to $1.67 \times$ $10^{10}$ colony forming units $(\mathrm{cfu}) / \mathrm{mL}$. The bacterial cell suspension was free of endotoxin as determined by a Limulus amebocyte lysate test (Associates of Cape Cod, Falmouth, MA, U.S.A.), which had a sensitivity of $>0.03 \mathrm{EU} / \mathrm{mL}$.

Drug preparation. Phosphoramidon (Peptides International, Louisville, KY) at a dose of $30 \mathrm{mg} / \mathrm{kg}$ was dissolved in $5 \mathrm{~mL}$ sterile water immediately before drug administration. This dose was selected based on the attenuation of pulmonary hypertension in young pigs under CPB (8).

Pulmonary hypertension protocol. Forty-eight to seventytwo hours following the surgery, the piglets were placed in an animal sling in a thermoneutral environment and exposed continuously to $100 \% \mathrm{O}_{2}$ via face mask. The piglets showed no signs of discomfort or agitation throughout the study period. After a stabilization period, baseline hemodynamic measurements (Ppa, Pwp, Pra, Psa, and CO) and ABG were obtained. GBS was then continuously infused into the femoral artery catheter at $3.6 \times 10^{8} \mathrm{cfu} / \mathrm{kg} / \mathrm{min}$. Fifteen minutes after sustained pulmonary hypertension, all measurements were repeated. The animals were then given a bolus dose of $5 \mathrm{~mL}$ normal saline as PL or phosphoramidon as ECEI according to the group they were assigned to. All the measurements were repeated $15 \mathrm{~min}$ after and then every $30 \mathrm{~min}$ thereafter, until death or study termination at $4 \mathrm{~h}$. At study conclusion, all animals were killed with an overdose of pentobarbital sodium.

Plasma ET-1 immunoassay. To ascertain the mechanism of action of phosphoramidon in this model, arterial plasma ET-1 levels were measured. Blood samples were collected at baseline before GBS infusion and after $3 \mathrm{~h}$ of GBS infusion in both PL $(n=10)$ and ECEI $(n=10)$ groups. Samples were centrifuged at $1,000 \times g$ at $4^{\circ} \mathrm{C}$ for $10 \mathrm{~min}$ and the plasma was frozen at $-70^{\circ} \mathrm{C}$ until assayed by ELISA (Parameter, R \& D Systems, Minneapolis, MN, U.S.A.). The plasma purification and assay were done following kit instructions. 
Statistical analysis. Data were analyzed using repeated measures ANOVA and analysis of covariance (ANCOVA) to compare the pattern of response between the ECEI and the PL groups, both over time (time-treatment interaction) and independent of time (overall group difference) for the dependent variables. ANCOVA was used for the comparison of PVR, $\mathrm{SVR}$, and $\mathrm{PaO}_{2}$ between groups. The 15 min post-GBS measurement was the covariate. Dependent variables included Ppa, Psa, CO, PVR, SVR, PVR/SVR, and ABG. Values used in the analysis included the time from bacterial infusion through 210 min. Significant mortality in the PL group prevented the analysis of data after this time period. Only data from 17 piglets were presented for PVR and PVR/SVR because of technical problems with displacement of the Swan-Ganz catheters in five of the animals. Survival data were analyzed using the MannWhitney test. Data were presented as mean $\pm \mathrm{SD}$, and a $p$ value $<0.05$ was considered significant.

\section{RESULTS}

Ten piglets (weight, $2.4 \pm 0.3 \mathrm{~kg}$; age, $8.3 \pm 0.8 \mathrm{~d}$ ) were treated with ECEI and 12 piglets (weight, $2.4 \pm 0.2 \mathrm{~kg}$; age, $8.4 \pm 1.0 \mathrm{~d}$ ) were given PL. There was no significant difference in age and weight between groups.

Baseline hemodynamic measurements before bacteria and 15 min after bacterial infusion were comparable between groups. Figure $1 \mathrm{~A}$ shows the changes in mean pulmonary artery pressure. Ppa increased $>2.5$ fold 15 min after GBS infusion in both groups (PL from $14.3 \pm 2.3$ to $37.0 \pm 4.0 \mathrm{~mm}$ $\mathrm{Hg}$ and ECEI from $13.4 \pm 2.7$ to $39.6 \pm 5.7 \mathrm{~mm} \mathrm{Hg}$ ). In the ECEI animals, there was a significant progressive attenuation in Ppa to $26.1 \pm 5.9 \mathrm{~mm} \mathrm{Hg}$ at $210 \mathrm{~min}$ (time-treatment interaction, $p<0.0001$ ), whereas in the PL animals, the Ppa remained elevated for the duration of the study. PVR increased soon after GBS infusion in both groups. In the ECEI group, PVR decreased after the ECEI was administered and reached a nadir around $90 \mathrm{~min}$, where it was sustained for the duration of the study. In the PL group, the PVR remained elevated until $2 \mathrm{~h}$ and progressively increased until study termination (timetreatment interaction, $p<0.001$ ) (Fig. $1 B$ ).

Figure $2 A$ shows the mean Psa. During GBS infusion, Psa slowly decreased over time in both groups and there was no significant difference between groups. The SVR, on the other hand, increased with bacterial infusion in both groups (15-min values were not significantly different between groups). In the ECEI group, the SVR gradually decreased and was maintained around baseline levels, whereas in the PL group, the decrease in SVR was not sustained because of the early mortality. There was, however, no significant difference between groups (Fig. $2 B)$.

To compare the relative effects of ECEI on the pulmonary and systemic vasculature, PVR/SVR was calculated. A similar increase in PVR/SVR was seen during GBS infusion in both groups. Whereas in the PL group the PVR/SVR continued to increase over time, in the ECEI group there was a significant sustained decrease in PVR/SVR after ECEI administration ( $p$ $<0.01$ ) (Fig. 3).
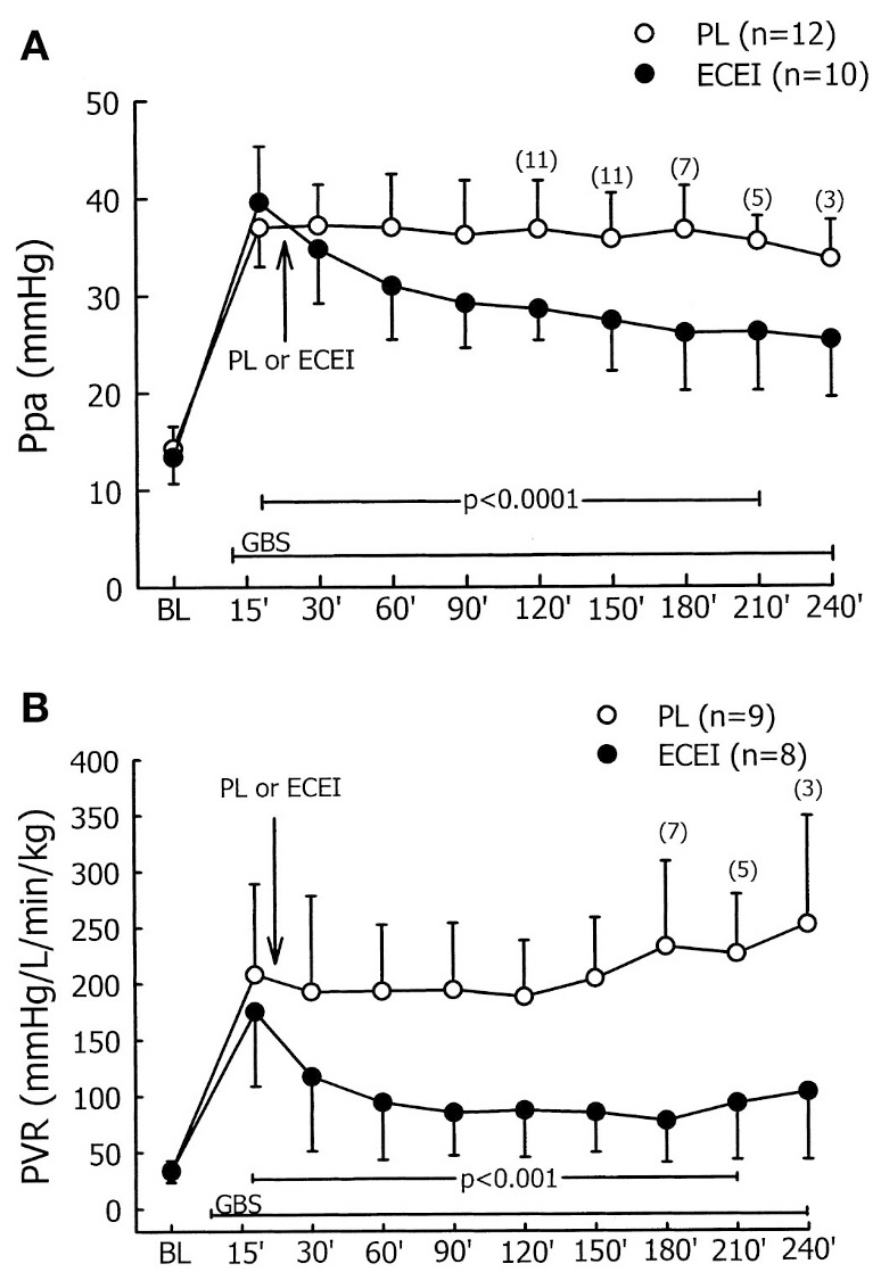

Figure 1. $(A)$ Values (mean $\pm \mathrm{SD}$ ) for mean Ppa during hyperoxia and GBS infusion before and after PL or ECEI administration. Ppa decreased significantly over time in the ECEI group. $(B)$ Values (mean \pm SD) for PVR during hyperoxia and GBS infusion before and after PL or ECEI administration. PVR decreased significantly over time in the ECEI group.

$\mathrm{CO}$ decreased markedly with the onset of GBS-induced pulmonary hypertension in both groups. In the ECEI group, the $\mathrm{CO}$ increased significantly soon after the ECEI administration and was sustained for the duration of the study. In the PL group, the decrease in $\mathrm{CO}$ was maintained for $2 \mathrm{~h}$ and further deteriorated for the rest of the study period (time-treatment interaction, $p<0.01$ ). [Fig. 4]

As seen in Table 1, $\mathrm{pH}$ and BE decreased significantly 15 min after GBS infusion in both groups. However, a more pronounced decrease in the $\mathrm{pH}(p<0.001)$ and $\mathrm{BE}(p<$ 0.001 ) over time was observed in the PL group compared with the ECEI animals. The changes in $\mathrm{PaCO}_{2}, \mathrm{PaO}_{2}, \mathrm{Pwp}$, Pra, heart rate, and stroke volume during GBS infusion were not different between groups.

Plasma ET-1 levels were similar in both the PL and ECEI groups at baseline before GBS infusion $(7.6 \pm 2.8 \mathrm{pg} / \mathrm{mL}$ versus $8.2 \pm 1.5 \mathrm{pg} / \mathrm{mL}$ ). After $3 \mathrm{~h}$ of GBS infusion, there was an elevation in the plasma ET-1 levels in both groups, however, this was significantly lower in the phosphoramidontreated animals compared with the PL group (32.6 \pm 13.8 $\mathrm{pg} / \mathrm{mL}$ versus $63.6 \pm 30.8 \mathrm{pg} / \mathrm{mL}, p<0.02)$. 
A

O $P L(n=12)$

ECEI $(n=10)$

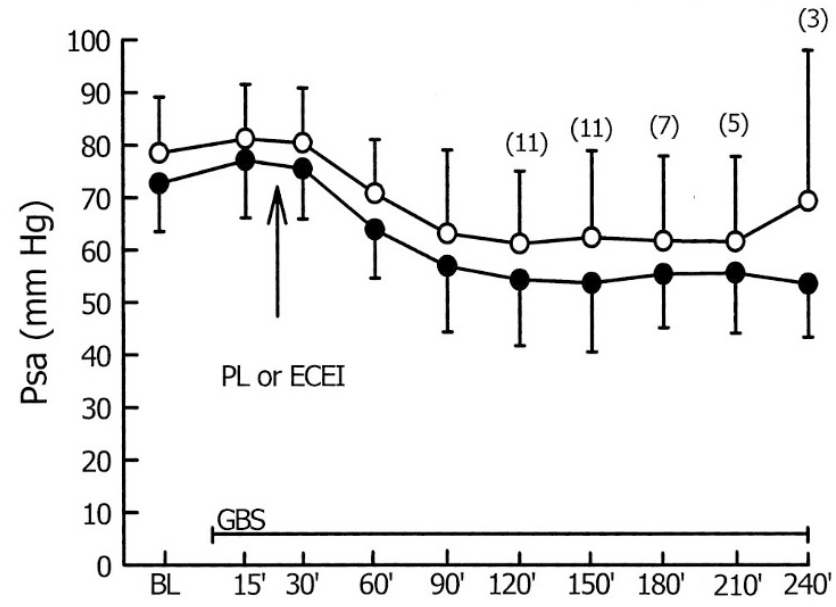

\section{B}

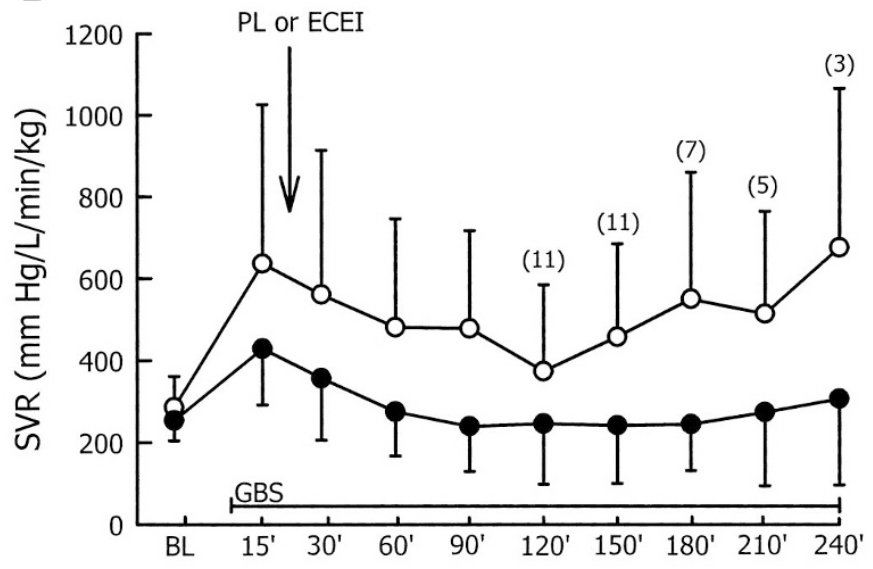

Figure 2. $(A)$ Values (mean $\pm \mathrm{SD}$ ) for mean Psa during hyperoxia and GBS infusion before and after PL or ECEI administration. Parallel decrease over time without any significant difference was observed between groups. $(B)$ Values (mean \pm SD) for SVR during hyperoxia and GBS infusion before and after PL or ECEI administration. Changes in SVR were not significant between groups.

In the PL group, only $25 \%$ of the animals survived the $4-\mathrm{h}$ study period, whereas all animals survived in the ECEI group $(p<0.001)$ (Fig. 5).

\section{DISCUSSION}

The present study showed that ET-1 is one of the mediators of the pulmonary hypertension induced by GBS infusion in the newborn piglet. The blockade of ECE with phosphoramidon was associated with decreased ET-1 levels, attenuation of pulmonary hypertension, improved $\mathrm{CO}$, better acid-base status, and prolongation of the survival time during GBS infusion in the unanesthetized newborn piglet.

As blockade of ECE inhibits the conversion of big ET to the potent pulmonary vasoconstrictor ET-1, and consequently de-

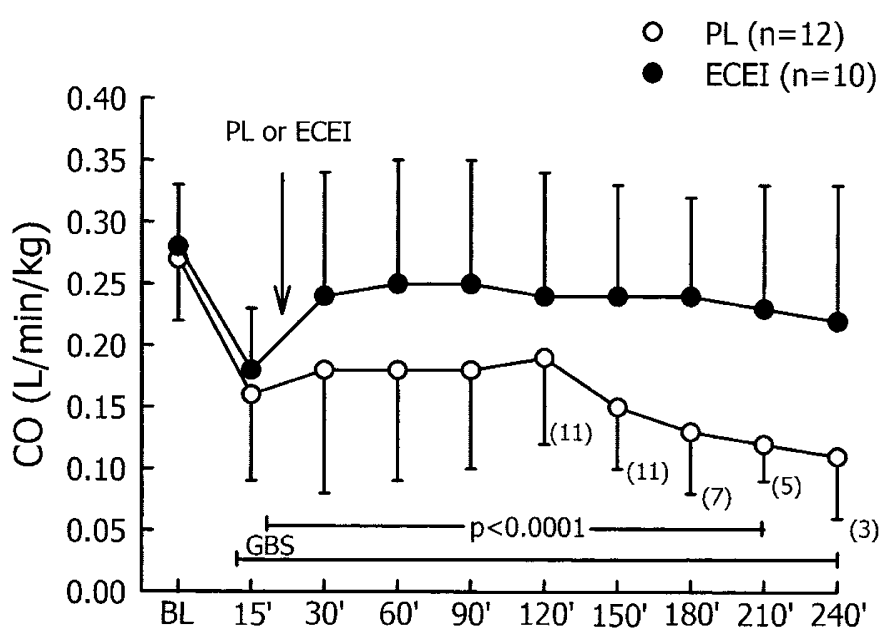

Figure 3. Values (mean $\pm \mathrm{SD}$ ) for $\mathrm{CO}$ during hyperoxia and GBS infusion before and after PL or ECEI administration. CO increased significantly over time in the ECEI group.

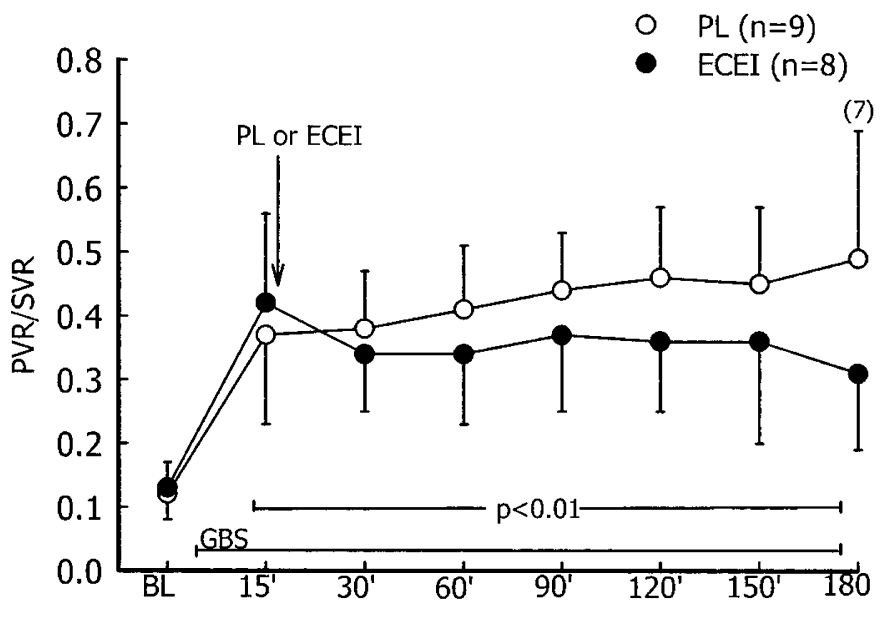

Figure 4. Values (mean $\pm \mathrm{SD}$ ) for PVR/SVR during hyperoxia and GBS infusion before and after PL or ECEI administration. There was a significant decrease in PVR/SVR in the ECEI group, whereas in the PL group it continued to elevate further.

creases the production of ET-1, this may have attenuated the pulmonary hypertension during GBS infusion. During pulmonary hypertension of various causes $(4,9)$, ET-1 levels have been demonstrated to be elevated. Disease severity correlated with the degree of ET-1 elevation and recovery from the illness occurred when ET-1 levels decreased. To the best of our knowledge, there are no published studies demonstrating the relationship between GBS-induced pulmonary hypertension and ET-1 levels. However, in a model of sterile meningitis induced by GBS injection into the cerebral lateral ventricle, this was associated with elevated levels of cerebrovascular ET-1 and or big ET-1 (14). Evidence also suggests that ET-1 is an important component of the inflammatory response to sepsis (15). ET-1 induces the production of cytokines such as tumor necrosis factor- $\alpha$, IL- $1 \alpha$, and IL- $1 \beta$. Furthermore, endotoxin, thromboxane, and interleukins among other mediators of inflammation have been described to stimulate the release of ET-1 (15). This may partially explain the observed elevation of ET-1 in this model of GBS-induced pulmonary hypertension. 
Table 1. Hemodynamic, blood gases, and acid base status values during hyperoxia and GBS infusion before and after PL or ECEI administration

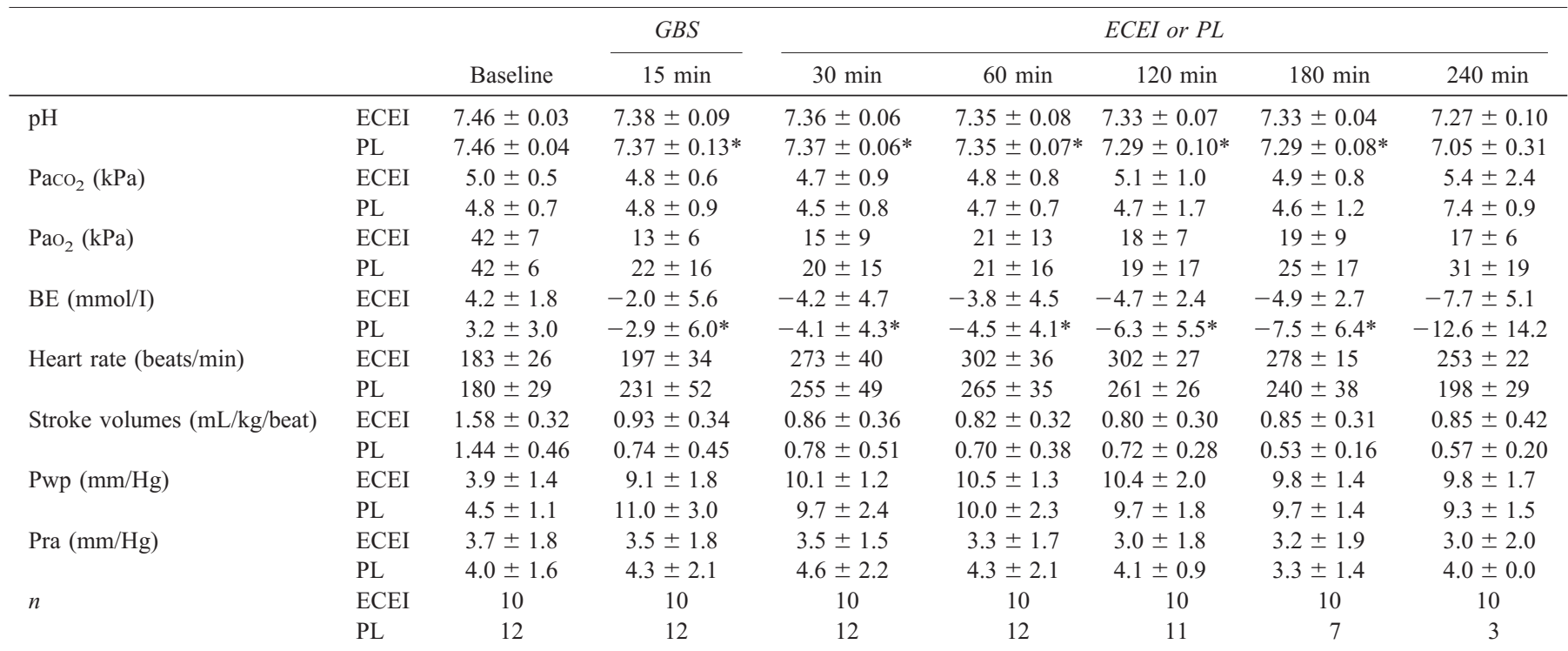

Mean \pm SD. $* p<0.05$ (PL $v s$ ECEI).

O PL $(n=12)$

- ECEI $(n=10)$

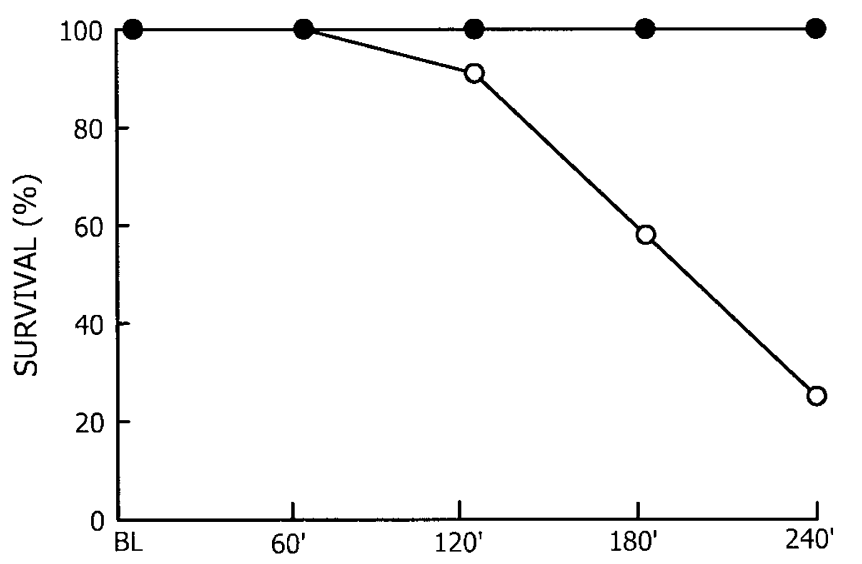

Figure 5. Percentage survival over time. All animals in the ECEI group survived the study period, whereas the PL group animals showed a significantly lower survival rate.

Endothelial breakdown $(15,16)$, pressure $(17)$, and hypoxia (18) are the other putative reasons. To eliminate any possible effect of hypoxemia on increasing ET-1 levels and on enhancing pulmonary vasoconstriction (7), the piglets were exposed to $100 \% \mathrm{O}_{2}$ throughout the study period.

Phosphoramidon, though a combined neutral endopeptidase (NEP)/ECE inhibitor, has been shown to decrease ET levels in cultured cell in vitro (19). It inhibits neutral endopeptidase 24.11 and other metalloproteases. Neutral endopeptidase 24.11 is an enzyme that normally catalyzes the degradation of angiotensin II, III, and I, bradykinin, and oxytocin $(8,20)$. In an in vivo model, phosphoramidon administered to young piglets before CPB decreased the magnitude of post-CPB pulmonary hypertension, indication that the administration of phosphoramidon attenuated pulmonary hypertension by decreasing the production of ET-1 (8). Also, because it has been demonstrated that pulmonary artery smooth cells exposed to ET-1 had an increased production of superoxide (21), and the latter has been associated with pulmonary vasoconstriction (22), then inhibition by phosphoramidon may decrease superoxide release. This effect may not be significant inasmuch as administration of superoxide dismutase did not attenuate GBS-induced pulmonary hypertension in the lamb (23). Additionally, during sepsis, there may be increased release of nitric oxide systemically (24, 25 ), which can result in increased peroxynitrite levels. Peroxynitrite has been shown to inhibit endothelial nitric oxide synthase (eNOS) activity, although the mechanism is unknown (21). Administration of phosphoramidon could therefore potentially decrease peroxynitrite generation and improve eNOS activity, and even further attenuate pulmonary hypertension.

A significant decline in arterial blood pressure was observed after GBS infusion in both groups. Different animal models using GBS showed varied effects on the systemic blood pressure, with greater tendency toward producing hypotension, especially during the later phase of the infection (13). It has been demonstrated that several mechanisms could contribute to this. First, sepsis and ET-1 stimulate the release of proinflammatory cytokines such as tumor necrosis factor- $\alpha$, platelet activating factor, and $\operatorname{IL}(15,26)$. The participation of these cytokines in the systemic inflammatory response syndrome and cardiovascular failure has been established and is described to contribute to the observed systemic hypotension $(9,15)$. Second, sepsis induces nitric oxide synthase (iNOS) in the endothelial and vascular smooth muscle cells, enhancing vasodilatation especially during the late phase of sepsis $(24,25)$. Moreover, Markewitz et al. (27) demonstrated that ET-1 decreased iNOS mRNA in cytokine-stimulated rat epithelial cells and this effect was reversed by phosphoramidon. The use of phosphoramidon as a nonselective NEP/ECE inhibitor might also affect or decrease degradation of atrial natriuretic peptide, an endogenous vasoactive peptide that induces vasodilatation. NEP inhibition has been previously associated with increased 
levels of atrial natriuretic peptide in the circulation (20) and, thereby, the net increase of vasodilators and systemic hypotension. This possible effect does not explain the similar reduction in Psa during GBS infusion between the PL and ECEI groups. In addition, the significant decrease in PVR/SVR over time observed after ECE inhibition suggests that phosphoramidon has a more predominant effect in the pulmonary than the systemic vasculature.

GBS in neonates is known to decrease cardiac output or produce "cold" shock (28). This was duplicated in the study, and it improved with ECE inhibition. This effect presumably is because of the decrease in ET-1 production, especially because ET-1 promotes coronary vasoconstriction through the $\mathrm{ET}_{\mathrm{A}}$ receptors $(9,29)$. Also, elevated thromboxane levels have been associated with the reduction in CO seen during GBS sepsis (30). Because ET-1 has been shown to potentiate the release of thromboxane, inhibition by phosphoramidon would be expected to decrease thromboxane release and thereby further improve cardiac output. Another explanation could be the afterload reduction, as seen in this study and in experiments with congestive heart failure and administration of $\mathrm{ET}_{\mathrm{A}}$ receptor antagonists $(7,31)$. Because ET-1 also produces negative inotropy (7), decreasing its production can improve CO.

The development of metabolic acidosis during GBS sepsis has been attributed to progressive tissue ischemia resulting from reduced oxygen delivery $(28,32,33)$. In the ECEI group, as a consequence of improvement in $\mathrm{CO}$, systemic $\mathrm{O}_{2}$ delivery is preserved, improving $\mathrm{O}_{2}$ utilization as reflected by a lesser degree of metabolic acidosis. Also, local tissue ischemia associated with the increased cytokine release (34) would be further lessened by phosphoramidon. This may have contributed to the improved survival during the study period.

In conclusion, the pulmonary hypertension observed during GBS infusion in newborn piglets is associated with elevation of plasma ET-1 levels and this was attenuated by the administration of an ECE inhibitor. This suggests that the pulmonary vasoconstriction is, in part, mediated by an increase in circulating levels of ET-1. The effect of the ECE inhibitor phosphoramidon was predominant in the pulmonary vasculature, because the PVR/SVR decreased significantly in the treated newborn piglets.

\section{REFERENCES}

1. Steinhorn RH, Millard SL, Morin III FC 1995 Persistent pulmonary hypertension of the newborn. Role of nitric oxide and endothelin in pathophysiology and treatment. Clin Perinatol 22:405-428

2. Walsh MC, Stork ER 2001 Persistent pulmonary hypertension of the newborn: rational therapy based on pathophysiology. Clin Perinatol 28:609-627

3. Ivy DD, Parker TA, Kinsella JP, Abman SH 1998 Endothelin A receptor blockade decreases pulmonary vascular resistance in premature lambs with hyaline membrane disease. Pediatr Res 44:175-180

4. Rosenberg AA, Kennaugh J, Koppenhafer SL, Loomis M, Chatfield BA, Abman SH 1993 Elevated immunoreactive endothelin-1 levels in newborn infants with persistent pulmonary hypertension. J Pediatr 123:109-114

5. Battistini B, Dussault P 1998 Blocking of the endothelin system: the development of receptor antagonists. Pulm Pharmacol Ther 11:97-112

6. Coe Y, Haleen SJ, Welch KM, Coceani F 2000 The endothelin A receptor antagonist PD 180988 (CI-1034) selectively reverses pulmonary vasoconstrictor response to hypoxia in the lamb. J Cardiovasc Pharmacol 36(suppl 1):S331-S333

7. Torre-Amione G, Young J, Durand JB, Bozkurt B, Mann DL, Kobrin I, Pratt CM 2001 Hemodynamic effects of tezosentan, an intravenous dual endothelin receptor antagonist, in patients with class III to IV congestive heart failure. Circulation 103:973-980

8. Kirshbom PM, Tsui SS, DiBernardo LR, Meliones JN, Schwinn DA, Ungerleider RM, William Gaynor J 1995 Blockade of endothelin-converting enzyme reduces pulmonary hypertension after cardiopulmonary bypass and circulatory arrest. Surgery 118:440-445

9. Pittet J, Morel D, Hemsen A 1991 Elevated plasma endothelin-1 concentrations are associated with the severity of illness in patients with sepsis. Ann Surg 213:261-264

10. Wanacek M, Rudehill A, Hemsen A, Lundberg JM, Weitzberg E 1997 The endothelin receptor antagonist, bosentan, in combination with the cyclooxygenase inhibitor, diclofenac, counteracts pulmonary hypertension in porcine endotoxic shock. Crit Care Med 25:848-857

11. Wanacek M, Oldner A, Sundin P, Alving K, Weitzberg E, Rudehill A 1999 Effects on hemodynamics by selective ETB receptor and combined endothelin ATA/ATB receptor antagonism during endotoxin shock. Eur J Pharmacol 386:235-245

12. Klein JO 2001 Bacterial sepsis and meningitis. In: Remington JS, Klein JO (eds) Infectious Diseases of the Fetus and Newborn Infant. WB Saunders, Philadelphia, pp 943-997

13. Meadow WL, Meus PJ 1986 Early and late hemodynamic consequences of group B beta streptococcal sepsis in piglets: effects on systemic, pulmonary, and mesenteric circulations. Circ Shock 19:347-356

14. Modanlou HD, Beharry K, Bottoli I, Raghavender B, Aranda JV 1996 Changes in cerebrospinal fluid and cerebrovascular endothelin concentrations during hypotension and hypertension in newborn piglets with induced sterile meningitis. Can J Physiol Pharmacol 74:368-375

15. Battistini B, Forget AM, Laight D 1996 Potential roles for endothelins in systemic inflammatory response syndrome with a particular relation to cytokines. Shock 5:167-183

16. Gibson RL, Nizet V, Rubens CE 1999 Group B Streptococcal $\beta$-hemolysin promotes injury of lung microvascular endothelial cells. Pediatr Res 45:626-634

17. Harrison VJ, Ziegler T, Bouzourene K, Suciu A, Silacci P, Hayoz D 1998 Endothelin-1 and endothelin converting enzyme-1 gene regulation by shear stress and flow-induced pressure. J Cardiovasc Pharmacol 31(suppl 1):S38-S41

18. Holm P, Liska J, Franco-Cereceda A 1998 The ETA receptor antagonist, BMS182874 , reduces acute hypoxic pulmonary hypertension in pigs in vivo. Cardiovasc Res 37:765-771

19. Ikegawa R, Matsumura Y, Tsukahara Y, Takaoka M, Morimoto S 1990 Phosphoramidon, a metalloproteinase inhibitor, suppresses the secretion of endothelin-1 from cultured endothelial cells by inhibiting a big endothelin-1 converting enzyme. Biochem Biophys Res Commun 171:669-675

20. Lainchbury JG, Nicholls MG, Espiner EA, Yandle TG, Richards AM 1998 Regional plasma levels of cardiac peptides and their response to acute neutral endopeptidase inhibition in man. Clin Sci 95:547-555

21. Wedgwood S, McMullan DM, Bekker JM, Fineman JR, Black SM 2001 Role for endothelin-1-induced superoxide and peroxynitrite production in rebound pulmonary hypertension associated with inhaled nitric oxide therapy. Circ Res 89:357-364

22. Weissmann N, Winterhalder S, Nollen M, Voswinckel R, Quanz K, Ghofrani HA, Schermuly RT, Seeger W, Grimminger F 2001 NO and reactive oxygen species are involved in biphasic hypoxic vasoconstriction of isolated rabbit lungs. Am J Physiol Lung Cell Mol Physiol 280:L638-L645

23. Carpenter D, Larkin H, Chang A, Morris E, O’Neill J, Curtis J 2001 Superoxide dismutase and catalase do not affect the pulmonary hypertensive response to group B streptococcus in the lamb. Pediatr Res 49:181-188

24. Vincent JL, Zhang H, Szabo C, Preiser JC 2000 Effects of nitric oxide in septic shock. Am J Respir Crit Care Med 161:1781-1785

25. Villamor E, Perez-Vizcaino F, Ruiz T, Leza JC, Moro M, Tamargo J 1995 Group B Streptococcus and E. coli LPS-induced NO-dependent hyporesponsiveness to noradrenaline in isolated intrapulmonary arteries of neonatal piglets. Br J Pharmacol 115:261-266

26. Pinheiro JMB, Pitt BR, Gillis CN 1989 Roles of platelet-activating factor and thromboxane in Group B Streptococcus-induced pulmonary hypertension in piglets. Pediatr Res 26:420-424

27. Markewitz BA, Michael JR, Kohan DE 1997 Endothelin-1 inhibits the expression of inducible nitric oxide synthase. Am J Physiol 272:L1078-L1083

28. Rudinsky BF, Meadow WL 1992 Relationship between oxygen delivery and metabolic acidosis during sepsis in piglets. Crit Care Med 20:831-839

29. Kiely DG, Cargill RI, Struthers AD, Lipworth BJ 1997 Cardiopulmonary effects of endothelin-1 in man. Cardiovasc Res 33:378-386

30. Runkle B, Goldberg RN, Streitfeld MM, Clark MR, Buron E, Setzer ES, Bancalari E 1984 Cardiovascular changes in group B streptococcal sepsis in the piglet: response to indomethacin and relationship to prostacyclin and thromboxane A2. Pediatr Res 18:874-878

31. Speiker LE, Mitrovic V, Noll G, Pacher R, Schulze MR, Muntwyler J, Schalcher C, Kiowski W, Luscher TF 2000 Acute hemodynamic and neurohumoral effects of selective ETA receptor blockade in patients with congestive heart failure. J Am Coll Cardiol 35:1745-1752

32. Meadow WL, Rudinsky BF, Strates E, Komar KJ 1987 Oxygen delivery, oxygen consumption, and metabolic acidosis during group B streptococcal sepsis in piglets. Pediatr Res 22:509-512

33. Barefield ES, Oh W, Stonestreet BS 1992 Group B Streptococcus-induced acidosis in newborn swine: regional oxygen transport and lactate flux. J Appl Physiol 72:272277

34. Hack C, Aarden L, Thijs L 1997 Role of cytokines in sepsis. In: Dixon F (ed) Advances in Immunology. Academic Press, San Diego, CA, pp 101-195 